\title{
STUDI KEANEKARAGAMAN JENIS TUMBUHAN LIANA SEBAGAI SUMBER PAKAN PRIMATA DI STASIUN PENELITIAN CABANG PANTI TAMAN NASIONAL GUNUNG PALUNG
}

(Diversity of Liana as a Source of Primates Feed in Cabang Panti Research Station-Gunung Palung National Park)

\section{Riduwan, Hari Prayogo, Lolyta Sisillia}

Fakultas Kehutanan Universitas Tanjungpura Pontianak. Jl. Daya Nasional Pontianak 78124 Email : masriduwan20@gmail.com

\section{Abstract}

Liana is a species of plant that has a way of growing by creeping, spreading, or hanging on its host, but its roots are still attached to the ground. Liana is one of the primate feeds in Cabang Panti Research Station. The riset was conducted from August 15 - September 152018 at the Cabang Panti Research Station-Gunung Palung National Park. This riset aims to obtain data on the diversity of liana species and is expected to provide data and information about the diversity of these plant species. The results showed in five habitat types namely the peat swamp forest habitat - freshwater swamps found 79 individuals, alluvial soil found 54 individuals, sandy rocks found 59 individuals, Lowland granite found 56 individuals and highland granite found 38 individuals. The total number of the five habitat types is 286 individuals from 21 genus/species.

Keywords: Cabang Panti Research Station, Diversity, Lianas Plants.

\section{PENDAHULUAN}

Stasiun Penelitian Cabang Panti merupakan suatu kawasan yang berada pada zona inti Taman Nasional Gunung Palung dengan luas sekitar 2.100 ha. Salah satu yang menarik pada kawasan ini adalah tumbuhan liana, keterdapatan liana pada kawasan ini ternyata dijadikan sebagai sumber pakan primata seperti Orangutan (Pongo pygmaeus), Kelasi/Lutung Merah (Presbytis rubicunda), Kelempiau (Hylobates albibarbis) dan Monyet Ekor Panjang (Macaca fascicularis). Liana merupakan tumbuhan yang berakar pada tanah, tetapi batangnya membutuhkan penopang dari tumbuhan lain agar dapat menjulang dan daunnya memperoleh cahaya matahari secara maksimal (Indriyanto, 2008).

Menurut Soerianegara dan Indrawan (1982) dalam indriyanto (2006) tumbuhan liana merupakan jenis tumbuhan merambat. Tumbuhan ini memiliki batang yang tidak beraturan dan lemah, sehingga tidak mendukung tajuknya. Adanya liana dihutan merupakan salah satu ciri khas hutan hujan tropis, terutama jenis liana berkayu.

Liana mempunyai peranan positif dan negatif untuk hutan dan lingkungannya. Peranan positif antara lain mencegah tumbangnya pohon akibat angin karena pertumbuhannya yang menjalar diantara pohon-pohon penopangnya dalam hutan, sebagai 
sumber pakan bagi satwa liar terutama primata dan sebagai alat pendukung bagi hewan yang melintas di pepohonan (Setia, 2009). Peran negatif liana adalah dapat menyebabkan kerusakan pada tempat tertentu pada tumbuhan penopang yang dipanjatnya seperti luka pada batang pohon (Asrianny $d k k$., 2008).

Jenis tumbuhan liana sebagai pakan primata di Stasiun Penelitian Cabang Panti masih belum begitu banyak yang diketahui keberadaannya, oleh sebab itu hal ini menarik untuk dilakukan sebuah peneltian. Tujuan umum penelitian ini adalah untuk mendapatkan data mengenai keanekaragaman jenis tumbuhan liana yang akan dilakukan pada lima tipe habitat yang berbeda, sedangkan tujuan khususnya adalah untuk mendapatkan data liana yang menjadi sumber pakan primata yang ada pada kawasan tersebut.

\section{METODE PENELITIAN}

Penelitian ini dilaksanakan selama kurang lebih 1,5 bulan waktu efektif di lapangan. Penelitian dilakukan pada kawasan Stasiun Penelitian Cabang Panti-Taman Nasional Gunung Palung di lima tipe habitat yang berbeda yaitu : habitat rawa gambut-rawa air tawar, tanah alluvial, batu berpasir, granit dataran rendah dan granit dataran tinggi. Ciri-ciri lima tipe habitat ini dijelaskan sebagai berikut :

1. Hutan rawa gambut-rawa air tawar

Gambut terbentuk dari timbunan sisa-sisa tanaman yang telah mati, baik yang sudah lapuk maupun belum. Timbunan terus bertambah karena proses dekomposisi terhambat oleh kondisi anaerob atau kondisi lingkungan lainnya yang menyebabkan rendahnya tingkat perkembangan biota pengurai. Pembentukan tanah gambut merupakan proses geogenik yaitu pembentukan tanah yang disebabkan oleh proses deposisi dan tranportasi, berbeda dengan proses pembentukan tanah mineral yang pada umumnya merupakan proses pedogenik (Hardjowigeno, 1986).

Perbedaan habitat hutan rawa gambut dan rawa air tawar pada stasiun penelitian cabang panti sebenarnya tidak terlalu banyak, yang membedakan hanya kondisi tekstur tanahnya. Rawa gambut kondisi tanahnya seperti lumpur dan dalam, sedangkan pada rawa air tawar kondisi tanahnya ada yang berlumpur dan ada yang agak keras.

2. Tanah alluvial

Alluvial adalah jenis tanah yang terbentuk karena endapan. Daerah endapan terjadi di sungai, danau yang berada di dataran rendah, ataupun cekungan yang memungkinkan terjadinya endapan. Letak habitat ini pada stasiun penelitian cabang panti antara hutan rawa gambut-rawa air tawar dan habitat batu berpasir. Ciri khas pada habitat ini banyak terdapat tumbuhan Stachyphrynium dari family Marantaceae dan di habitat ini paling banyak dijumpai hewan pacet.

3. Habitat tanah batu berpasir

Tanah pasir adalah tanah dengan partikel berukuran besar. Tanah ini terbentuk dari batuan-batuan beku serta batuan sedimen yang memiliki butiran besar dan kasar atau yang sering disebut dengan kerikil. Tanah pasir memiliki 
kapasitas serat air yang rendah karena sebagian besar tersusun atas partikel berukuran 0,02 sampai $2 \mathrm{~mm}$. Batu pasir dapat memiliki berbagai jenis warna, dengan warna umum adalah coklat muda, coklat, kuning, merah, abu-abu dan putih. Kawasan stasiun penelitian cabang panti warna batu pasir berwana putih.

4. Habitat granit dataran rendah dan granit dataran tinggi

Letak habitat ini berada pada ketinggian 200 hingga 800 mdpl, banyak dijumpai tumbuhan kantong semar (Nepenthes) namun tumbuhan liana di habitat ini sedikit dijumpai jika dibandingkan dengan tiga habitat lainnya.

Alat dan bahan yang diperlukan yaitu peta lokasi penelitian, GPS, meteran, tali raffia, pita tagging, kamera, binocular, parang, dan tally sheet. Objek penelitian adalah semua jenis tumbuhan liana yang ada di dalam plot yang telah dibuat. Alat dan bahan yang dibutuhkan untuk pembuatan herbarium yaitu koran, alkohol, plastik packing, pisau/gunting, lakban dan label.

Penelitian ini menggunakan metode Random Sampling untuk menentukan lokasi penelitian dan dikombinasikan dengan Belt Transect untuk menentukan panjang jalurnya. Menurut Fachrul (2007) Belt Transect adalah jalur sempit yang melintang pada lahan yang akan dipelajari atau diselidiki. Panjang jalur yang digunakan adalah jalur utama dengan panjang 50 meter dan jalur plot sebelah kanan/kiri masing-masing 10 meter.

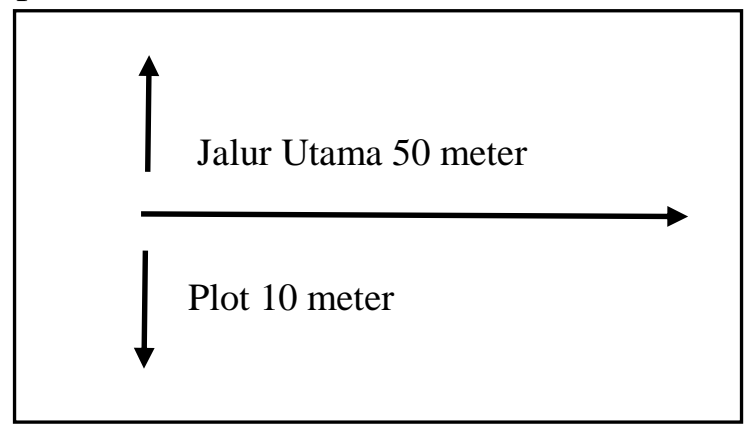

Gambar 1. Sketsa Jalur Penelitian (Research Path Sketch)

\section{Analisis Data}

1. Indeks Dominansi (Sympson index)

Untuk menentukan dominasi satu jenis tumbuhan liana yang terpusat dalam komunitas di gunakan rumus sebagai berikut (Odum, 1993)

$$
C=\Sigma\left[\frac{\mathbf{n i}}{\mathbf{N}}\right]^{2}
$$

Dimana :

C : Indeks Dominansi ni : Jumlah Individu Suatu Jenis

N : Jumlah Individu Seluruh Jenis

2. Indeks keanekaragaman ShannonWiener $(\overline{\mathrm{H}})$

Indeks keanekaragaman jenis $(\overline{\mathrm{H}})$ adalah suatu jenis indeks secara keseluruhan dapat ditentukan dengan rumus Shanon-Wiener (Odum, 1993; Soegianto, 1994) sebagai berikut:

$$
\overline{\mathrm{H}}=-\sum\left[\frac{\mathrm{ni}}{\mathrm{N}}\right] \log \left[\frac{\mathrm{ni}}{\mathrm{N}}\right]
$$


Dimana :

$\overline{\mathrm{H}} \quad$ : Indeks keanekaragaman ShanonWienner.

ni : Jumlah individu suatu jenis

$\mathrm{N}$ : Jumlah individu seluruh jenis

Besarnya indeks keanekaragaman jenis menurut Shanon-Wienner didefinisikan sebagai berikut :

Nilai $\overline{\mathrm{H}}=$

$0 \leq \bar{H} \leq 1,5$ Kenekaragaman rendah

$1,5 \leq \bar{H} \leq 3,5$ Kenekaragaman sedang

$\bar{H} \geq 3,5$ Keanekaragaman tinggi

3. Indeks Kemerataan (e)

Untuk menentukan apakah individuindividu terdistribusi secara lebih merata pada jenis-jenis yang hadir pada suatu tingkat pertumbuhan, maka ditentukan indeks kemerataan (e) menurut Pielou (1966) dalam Odum (1993) dengan rumus sebagai berikut:

$$
e=\frac{H}{\log S}
$$

Dimana :

e : Indeks kemerataan

$\mathrm{H}$ : Indeks keanekaragaman Shanon-

Wiener

S : Jumlah jenis yang teramati

4. Indeks Kekayaan Jenis

Merupakan nilai atau rasio perbandingan jenis antara jumlah jenis secara keseluruhan terhadap jumlah individu jenis yang dijumpai (Odum, 1993) dengan rumus sebagai berikut :

$$
\mathrm{d}=\frac{S-1}{\log N}
$$

Dimana :

d : Indeks kekayaan jenis

S : Jumlah jenis yang teramati

$\mathrm{N}$ : Jumlah individu seluruh jenis
Indeks kekayaan jenis untuk nilai lebih dari 3,5 digolongkan tinggi, nilai indeks 1,5-3,5 digolongkan sedang, dan nilai indeks dibawah 1,5 digolongkan rendah.

5. Indeks Kesamaan Jenis

Untuk mengetahui besarnya indeks kesamaan dapat digunakan rumus sebagai berikut (Odum,1993) :

$$
\text { IS }=\frac{2 C}{A+B} \times 100 \%
$$

Dimana :

A = Jumlah jenis pada lokasi $\mathrm{A}$

$\mathrm{B}=$ Jumlah jenis pada lokasi $\mathrm{B}$

$\mathrm{C}=$ Jumlah jenis yang sama pada

lokasi A dan B

IS = Indeks Kesamaan Jenis

Kriteria Indeks Kesamaan Komunitas menurut Odum (1993) :

$1-30 \%=$ Kategori rendah

$31-60 \%=$ Kategori sedang

$61-91 \%=$ Kategori tinggi

$>91 \%=$ Kategori sangat tinggi

HASIL DAN PEMBAHASAN

\section{Struktur Jenis Tumbuhan Liana Pada} Masing-masing Habitat

Jenis tumbuhan liana yang dijumpai pada 5 tipe habitat ditemukan adanya variasi untuk masing-masing habitat yang diamati. Habitat hutan rawa gambut-rawa air tawar ditemukan sebanyak 79 individu yang terdiri dari 15 genus dan didominasi oleh jenis Artabotrys sp. Menurut Nurainas (2003) tumbuhan ini dapat dijumpai pada habitat hutan dataran rendah, hutan tropis pegunungan dengan ketinggian mencapai 1.100 mdpl dan tersebar di India, Filipina, Malaysia, dan Indonesia. Tumbuhan ini di Indonesia tersebar di pulau Jawa, Sulawesi, Sumatra dan Kalimantan. Habitat tanah alluvial ditemukan sebanyak 54 individu yang terdiri atas 13 genus dan didominasi 
oleh jenis liana Strychnos sp. Habitat batu berpasir ditemukan sebanyak 59 individu yang terdiri atas 14 genus dan didominasi oleh jenis liana Artabotrys sp. Habitat granit dataran rendah ditemukan sebanyak 56 individu yang terdiri atas 9 genus dan didominasi oleh jenis liana Strychnos $s p$., dan pada habitat granit dataran tinggi ditemukan sebanyak 38 individu yang terdiri atas 4 genus dan didominasi oleh jenis liana Strychnos sp.

Berdasarkan jumlah jenis tumbuhan liana yang ditemukan pada ke lima tipe habitat tersebut terlihat bahwa tumbuhan liana banyak ditemukan pada habitat hutan rawa gambut-rawa air tawar, tanah alluvial, batu berpasir dan granit dataran rendah sehingga memungkinkan ke empat habitat ini adalah tempat yang cocok untuk tumbuhan liana hidup. Habitat granit dataran tinggi ditemukan tumbuhan liana dengan jumlah paling sedikit dan dengan variasi juga sedikit. Waktu pelaksanaan penelitian primata banyak ditemukan pada habitat rawa gambut-rawa air tawar, tanah alluvial, dan juga batu berpasir karena pada lokasi ini ada banyak sumber pakan primata yang sedang berbuah termasuk tumbuhan liana.

Jenis-jenis tumbuhan liana yang telah ditemukan pada semua tipe habitat dapat dilihat pada tabel 1 berikut :

Tabel 1. Daftar Tumbuhan Liana yang Ditemukan pada Seluruh Tipe Habitat (List of Liana Plants Found in All Habitat Types)

\begin{tabular}{|c|c|c|c|c|}
\hline No. & Famili & Genus & Nama Lokal & Total \\
\hline 1 & Ancistrocladaceae & Ancistrocladus $s p$ & & 10 \\
\hline 2 & Annonaceae & Artabotrys $s p$ & & 48 \\
\hline 3 & Annonaceae & Desmos sp & & 4 \\
\hline 4 & Annonaceae & Friesodielsia $s p$ & & 1 \\
\hline 5 & Annonaceae & Uvaria & & 3 \\
\hline 6 & Apocynaceae & Willughbeia $s p$ & Jantak & 40 \\
\hline 7 & Connaraceae & Agelaea $s p$ & & 10 \\
\hline 8 & Combretaceae & Combretum $s p$ & & 26 \\
\hline 9 & Connaraceae & Connarus sp & & 3 \\
\hline 10 & Connaraceae & Rourea sp & & 1 \\
\hline 11 & Fabaceae & Bauhinia $s p$ & Tapal Kaki Kuda & 13 \\
\hline 12 & Fabaceae & Derris sp & & 5 \\
\hline 13 & Fabaceae & Whitfordiodendron $s p$ & & 2 \\
\hline 14 & Fabaceae & Spatholobus sp & & 4 \\
\hline 15 & Gnetaceae & Gnetum $s p$ & & 15 \\
\hline 16 & Loganiaceae & Strychnos $s p$ & & 61 \\
\hline 17 & Malvaceae & Byttneria sp & & 2 \\
\hline 18 & Malvaceae & Grewia $s p$ & & 5 \\
\hline 19 & Rubiaceae & Uncaria sp & Cakar Elang & 28 \\
\hline 20 & Vitaceae & Ampelocissus sp & & 2 \\
\hline 21 & Vitaceae & Tetrastigma $s p$ & & 3 \\
\hline
\end{tabular}

Daftar data tumbuhan liana yang disajikan pada tabel 1 ada sekitar 18 genus yang menjadi sumber pakan primata di Stasiun Penelitian Cabang
Panti. Kawasan Stasiun Penelitian Cabang Panti terdapat 4 jenis primata yang menjadi prioritas utama untuk diteliti yaitu Orangutan, Kelasi/Lutung 
Merah, Kelempiau, dan Monyet Ekor Panjang. Keempat primata ini memanfaatkan tumbuhan liana sebagai sumber pakan. Pemanfaatan liana oleh primata tidak hanya buahnya saja, tetapi bagian yang dimakan ada juga bagian daun muda, pucuk daun, kulit batang dan bunga. Liana sebagai pakan primata dan bagian yang dimakan disajikan pada tabel 2 berikut.

Tabel 2. Daftar Tumbuhan Liana dan Bagian yang Dimakan Oleh Primata (List of Liana Plants and Parts Eaten by Primates)

\begin{tabular}{|c|c|c|c|c|c|}
\hline \multirow{2}{*}{ No. } & \multirow{2}{*}{ Nama Jenis } & \multicolumn{4}{|c|}{ Bagian yang Dimakan } \\
\hline & & Orangutan & Kelasi & Kelempiau & Monyet Ekor Panjang \\
\hline 1 & Agelaea sp & A dan $\mathrm{C}$ & - & - & - \\
\hline 2 & Ampelocissus $s p$ & A & - & - & - \\
\hline 3 & Artabotrys $s p$ & A & A & A & A \\
\hline 4 & Bauhinia sp & - & A dan $C$ & - & - \\
\hline 5 & Combretum sp & - & $\mathrm{C}$ & - & - \\
\hline 6 & Connarus sp & $\mathrm{D}$ & - & - & - \\
\hline 7 & Derris sp & A dan $\mathrm{C}$ & - & - & - \\
\hline 8 & Desmos sp & - & A dan $C$ & A & - \\
\hline 9 & Friesodielsia $s p$ & A & A & A & A \\
\hline 10 & Gnetum $s p$ & A & A & - & - \\
\hline 11 & Grewia $s p$ & $\mathrm{~A}, \mathrm{C}$ dan $\mathrm{E}$ & $A \operatorname{dan} E$ & A dan $E$ & - \\
\hline 12 & Rourea sp & C dan D & - & - & - \\
\hline 13 & Spatholobus sp & A dan B & - & - & - \\
\hline 14 & Strychnos sp & A & A dan $C$ & A dan $\mathrm{C}$ & - \\
\hline 15 & Tetrastigma $s p$ & A & A & - & - \\
\hline 16 & Uvaria $s p$ & A & - & - & A \\
\hline 17 & Whitfordiodendron $s p$ & $\mathrm{D}$ & - & - & - \\
\hline 18 & Willughbeia $s p$ & $A$ dan B & A dan $C$ & A & A \\
\hline \multicolumn{6}{|c|}{ Keterangan : } \\
\hline A : & & $\mathrm{C}: \mathrm{l}$ & In Muda & \multicolumn{2}{|c|}{ E : Bunga } \\
\hline & ucuk Batang & $\mathrm{D}: 1$ & it Batang & & \\
\hline
\end{tabular}

Berdasarkan tabel 2 terlihat bahwa primata Orangutan lebih banyak mendominasi memanfaatkan tumbuhan liana sebagai sumber pakannya dibandingkan 3 primata lainnya. Hal ini dikarenakan orangutan memiliki tubuh yang besar dan membutuhkan asupan makanan yang lebih banyak jika dibandingkan primata lainnya. Bahkan hingga saat ini penelitian tentang orangutan masih dilakukan penelitian, berbeda dengan 3 primata lainnya yang sudah tidak dilakukan penelitian secara intensive.

\section{Struktur Jenis Tumbuhan Liana Pada Masing-masing Habitat.}

Berdasarkan hasil penelitian di lima tipe habitat yang berbeda dijumpai sebanyak 21 genus dengan jumlah total secara keseluruhan ada 286 individu. Masing-masing tipe habitat memiliki struktur jenis tumbuhan liana yang berbeda-beda.

Indek Dominansi jenis tumbuhan liana tertinggi terdapat pada habitat granit dataran tinggi yaitu $\mathrm{C}=0.18$ dari genus liana Strychnos sp. Keanekaragaman jenis tumbuhan liana tertinggi terdapat pada habitat tanah alluvial $\overline{\mathrm{H}}=1.01$, Indeks kemerataan jenis tertinggi terdapat pada habitat tanah alluvial yaitu e $=0.91$, dan Indeks Kekayaan jenis tertinggi 
terdapat pada habitat hutan rawa gambut-rawa air tawar yaitu $d=14.47$. Nilai indeks tersebut dapat dilihat pada tabel 3 berikut.

Tabel 3. Indeks Dominansi, Indeks Keanekaragaman Jenis, Indeks Kekayaan Jenis dan Ke-merataan Jenis (Dominance Index, Species Diversity Index, Type Wealth Index and Evenness Type)

\begin{tabular}{lccccc}
\hline \multirow{2}{*}{ Indeks } & \multicolumn{5}{c}{ Tipe Habitat } \\
\cline { 2 - 6 } & $\mathbf{1}$ & $\mathbf{2}$ & $\mathbf{3}$ & $\mathbf{4}$ & $\mathbf{5}$ \\
\hline Dominansi (C) & 0.04 & 0.04 & 0.06 & 0.14 & 0.18 \\
Keanekaragaman (H) & 1 & 1.01 & 0.97 & 0.77 & 0.53 \\
Kekayaan (d) & 14.47 & 12.42 & 13.44 & 8.43 & 3.37 \\
Kemerataan (e) & 0.85 & 0.91 & 0.84 & 0.81 & 0.87 \\
\hline
\end{tabular}

\section{Keterangan :}

1 : Hutan rawa gambut-rawa air tawar

2 : Tanah alluvial

3 : Batu berpasir

Nilai indeks dominansi setiap habitat memiliki nilai dominansi yang berbeda-beda. Nilai indeks dominansi mendekati satu (1) apabila komunitas didominasi oleh jenis atau spesies tertentu dan jika indeks dominansi mendekati nol (0) maka tidak ada jenis atau spesies yang mendominasi (Odum, 1971). Berdasarkan tabel 3 terlihat jelas bahwa pada habitat granit dataran tinggi indeks dominansi memiliki nilai tertinggi yaitu $\mathrm{C}=0.18$. Hal ini dikarenakan tumbuhan liana jenis Strychnos sp. dijumpai dalam jumlah yang banyak yaitu sekitar 16 individu dan berbeda dengan jenis yang lainnya. Menurut Heyne (1987) ada salah satu tumbuhan yang memiliki genus Strychnos $s p$. yaitu tumbuhan bidara laut/kayu ular (Strychnos ligustrina Blume) yang ditemukan di Provinsi Nusa Tenggara Barat (NTB) bahwa Tumbuhan ini dapat tumbuh pada ketinggian 1-1500 mdpl.

Keanekaragaman jenis menggambarkan tingginya tingkat
4 : Granit dataran rendah

5 : Granit dataran tinngi

keanekaragaman yang terdapat pada suatu kawasan. Semakin tinggi nilai indeks keanekaragaman jenis $(\overline{\mathrm{H}})$, maka semakin banyak jenis-jenis yang terdapat pada kawasan tersebut. Nilai ini bertolak belakang dengan nilai indeks dominansi, apabila nilai indeks dominansi pada habitat tertentu mendekati 1 atau lebih makan nilai indeks keanekaragamannya semakin kecil dan sebaliknya apabila nilai indeks dominansi mendekati 0 maka nilai indeks keanekaragamnnya semakin besar. Besarnya nilai indeks keanekaragaman jenis menurut Shannon-Wienner didefinisikan sebagai berikut ; jika nilai $\mathrm{H}$ : $0 \leq \overline{\mathrm{H}} \leq 1,5$ tergolong rendah, jika nilai $\mathrm{H}: 1,5 \leq \overline{\mathrm{H}} \leq$ 3,5 tergolong sedang, dan jika nilai $\overline{\mathrm{H}} \geq$ 3,5 maka tergolong tinggi. berdasarkan tabel 3 semua nilai indeks keanekaragaman jenis masih tergolong rendah karena nilai $\mathrm{H}=1.01$ pada habitat tanah alluvial. Hal ini dikarenakan pada habitat tanah alluvial jenis tumbuhan liana yang ditemukan jumlahnya hampir 
sama rata dan tidak ada jenis tumbuhan liana yang ditemukan secara mencolok.

Berdasarkan hasil perhitungan Indeks Kekayaan Jenis (d), terdapat nilai-nilai yang sangat beragam yaitu pada habitat hutan rawa gambut-rawa air tawar $\mathrm{d}=14.47$, pada habitat tanah alluvial $\mathrm{d}=12.42$, pada habitat batu berpasir $\mathrm{d}=13.44$, pada habitat granit dataran rendah $\mathrm{d}=8.43$ dan pada habitat granit dataran tinggi $\mathrm{d}=3.37$. Hasil Indeks Kekayaan Jenis (d) tersebut dapat diketahui bahwa nilai yang tertinggi terdapat pada habitat hutan rawa gambut-rawa air tawar dikarenakan pada habitat ini banyak dijumpai tumbuhan liana dibandingkan dengan tipe habitat yang lainnya.

Hasil perhitungan indeks kemerataan jenis (e) tumbuhan liana pada habitat hutan rawa gambut-rawa air tawar nilai $\mathrm{e}=0.85$, pada habitat tanah alluvial nilai e $=0.91$, pada habitat batu berpasir nilai $\mathrm{e}=0.85$, pada habitat granit dataran rendah nilai $\mathrm{e}=0.81$ dan pada habitat granit dataran tinggi nilai e $=0.88$. Berdasarkan nilai tersebut maka indeks kemerataan jenis (e) pada lima tipe habitat tersebut kelimpahannya tidak merata. Menurut Odum (1993), indeks kemerataan jenis (e) berkisar antara $0-1$, jika e > 1 maka seluruh jenis yang ada memiliki kelimpahan yang sama atau merata, sedangkan jika e $<1$ maka seluruh jenis yang ada kelimpahan tidak merata.

Perbedaan juga terlihat pada komposisi nilai kesamaan jenis tumbuhan liana dari hasil pengamatan pada habitat hutan rawa gambut-rawa air tawar, tanah alluvial, batu berpasir, granit dataran rendah dan granit dataran tinggi. Perhitungan Indeks Kesamaan Jenis (IS) dapat dilihat pada Table 4 berikut :

Tabel 4. Indeks Kesamaan Jenis Liana antar Habitat (Similarity Index of Liana Species between Habitats

\begin{tabular}{ccc}
\hline No. & Habitat & IS \\
\hline 1 & $1-2$ & $57,14 \%$ \\
2 & $1-3$ & $68,96 \%$ \\
3 & $1-4$ & $50 \%$ \\
4 & $1-5$ & $31,57 \%$ \\
5 & $2-3$ & $66,66 \%$ \\
6 & $2-4$ & $72,72 \%$ \\
7 & $2-5$ & $47,05 \%$ \\
8 & $3-4$ & $60,86 \%$ \\
9 & $3-5$ & $44,44 \%$ \\
10 & $4-5$ & $61,53 \%$ \\
\hline
\end{tabular}

Keterangan :

1 = Rawa gambut - rawa air tawar

$2=$ Tanah alluvial

$3=$ Batu berpasir $\quad 5=$ Granit dataran tinggi

$4=$ Granit dataran rendah 
Berdasarkan perhitungan indeks kesamaan jenis pada tabel 4 dapat diketahui bahwa indeks kesamaan jenis ada yang dikategorikan sedang dan tinggi. Menurut Odum (1993) kriteria pada tabel diatas berada di antara 31-60 $\%$ (sedang) dan 61-91 \% (tinggi). Besar kecilnya nilai indeks kesamaan jenis dipengaruhi oleh seberapa banyak kesamaan jenis tumbuhan liana tersebut pada 2 habitat yang dibandingkan.

\section{KESIMPULAN}

Berdasarkan hasil penelitian yang dilakukan pada 5 tipe habitat yang berbeda telah dijumpai tumbuhan liana sebanyak 286 individu yang terdiri atas 21 genus, dari total 21 genus tersebut ada 18 genus yang masuk kedalam sumber pakan primata. Keanekaragaman jenis tumbuhan liana yang tertinggi terdapat pada tipe habitat tanah alluvial dengan nilah $\mathrm{H}=1,01$. Hal ini dikarenakan pada habitat tersebut jumlah jenis tumbuhan liana yang dijumpai hampir sama rata jika dibandingkan dengan tipe habitat yang lainnya.

\section{DAFTAR PUSTAKA}

Asrianny, Marian, dan NP. Oka. 2008. Keanekaragaman dan kelimpahan jenis liana (tumbuhan memanjat) pada hutan alam di hutan pendidikan Universitas Hasanuddin. Jurnal Perennial. Makasar. 5(1):23-30 p.
Fachrul MF. 2007. Metode Sampling Bioekologi. Jakarta: Bumi Aksara.

Hardjowigeno S. 1986. Sumber daya fisik wilayah dan tata guna lahan: Histosol. Fakultas Pertanian Institut Pertanian Bogor.

Heyne K. 1987. Tumbuhan Berguna Indonesia. Jilid I dan II. Terj.Badan Libang Kehutanan. Cetakan I. Koperasi karyawan Departemen Kehutanan Jakarta Pusat.

Indriyanto. 2008. Ekologi Hutan. Buku. Bumi Aksara. Jakarta. 210 p

Nurainas. 2003. Artabotrys (Annonaceae) In Sumatra. Tesis Master pada Institut Pertanian Bogor.

Odum EP. 1971. Dasar-dasar Ekologi. Gadjah Mada University Press. Yogyakarta.

Odum EP. 1993. Dasar-dasar Ekologi. Edisi Ketiga. Gajah Mada Univ. Press. Yogyakarta.

Setia TM. 2009. Peran liana dalam kehidupan orangutan. Jurnal penelitian dan pengembangan hutan. Jakarta.

Soegianto A. 1994. Ekologi Kuantitatif. Surabaya: Penerbit Usaha Nasional.

Soeranegara I dan A Indrawan 1982. Ekologi Hutan Indonesia. Departemen Manajemen Hutan Fakultas Kehutanan Institusi Pertanian Bogor, Bogor. 